\title{
Analysis of the Application of Compensation Management in the Enterprise Management of Public Hospitals
}

\author{
Shi Han \\ School of Education, Tianjin University \\ Tianjin, China \\ 695002308@qq.com
}

\begin{abstract}
Public hospitals, as an important part of the institution system of our country, are promoting the development of and enhancing the vitality of the organization. In recent years, it has gradually tended to adopt the enterprise management model. However, due to historical and other factors, problems resulted by poor salary incentives have a negative effect on the realization of organizational goals. In this regard, this paper focuses on the status quo of the salary system of public hospitals in China, points out and analyzes the relevant knowledge of enterprise salary management, and finally overcomes its shortcomings so as to improve the salary system of public hospitals as well as the level of incentives.
\end{abstract}

Keywords-Public hospital; Enterprise management; Salary management; Incentive

\section{ANALYSIS OF THE CURRENT SITUATION OF SALARY MANAGEMENT IN PUBliC Hospitals IN CHINA}

Since the reform and opening up, China's medical and health undertakings has been steadily developed under the strong support of the government. Not only reflected in the substantial improvement of medical technology level, but also in the progress made in the medical institution system. With the growth of China's economy and the continuous improvement of the marketization, public hospitals should break the shackles of the original management model and learn from the experience of enterprise management in order to adapt to the increasingly fierce market competition and the increasingly severe social situation. The hospital is a labor and technology intensive industry. The medical staff in the hospital is the most important factor in the hospital. So the problem of the doctor's salary management must be the most important part of the hospital management. It is worth noting that, although the enterprise management is the direction of the reform of public hospitals at the present stage, as a nonprofit enterprise in the broad sense, public hospitals must combine the characteristics of the industry and the hospital situation when exploring the suitable management road for themselves, blind imitation is not advisable, and it adds difficulty for the salary management of the hospital. Through investigation, we find that there are some problems in the salary management of public hospitals in China:
First, the design of the cross compensation system is unbalanced. The salary system of public hospitals in China tends to be a skill-based pay system but not thorough enough, resulting in the imbalance of cross compensation system design. This is because the factors affecting salary are hard indicators such as working age and professional title. Although these indicators have a certain relationship with the professional skills of doctors, they are influenced by factors such as seniority, scientific research results and literature. This kind of salary system makes young employees erroneously form the idea of "getting older and more popular" and "professional title is big", so that the focus of work is deviated from the right track.

Second, the allocation of performance-based wages is not reasonable. The performance evaluation of the hospital in China is mainly related to the number of patients received and the amount of their consumption. As a knowledge and technology intensive industry, if the performance-based wage is solely determined to the economic indicators in the production industry, which makes it difficult to embody the status of knowledge, technology, management and other factors in distribution, it's not reasonable. Nowadays, the phenomenon of "large prescriptions, multiple examinations" has become a major problem in the medical profession. In order to get good performance-based wages, a handful of doctors prescribe expensive medicine and unnecessary medicine, aggravating the burden of patients, damaging the public image of doctors and hospital, making the relationship between doctors and patients worse and worse, and eventually cause the loss of the whole society. In addition, "gray income" such as drug kickbacks is also a "complication" of this disease, and it is a challenge to national laws.

Third, the salary structure is misaligned and there is insufficient attention to non-economic compensation. Hospital work is generally high risk, high intensity, and knowledge is updated rapidly. Doctors are always in a state of high work pressure. Therefore, it can be very helpful for doctors to provide a good working and living environment, give them humanistic care, and use non-economic compensation properly to relieve stressful working emotions and improve work efficiency. Doctors in public hospitals in China are generally lack holidays and work atmosphere is tight, these factors have 
increased the pressure on doctors to a certain extent, and have a negative effect on employee job satisfaction.

Fourth, medical students have a serious problem of turnover, and the hospital's fresh blood has been lost year after year. Between 2004 and 2015, there were 4.728 million higher medical graduates in China, while the number of professional physicians growing during the same period was 752,000. This means that nearly $85 \%$ of medical students will choose to switch to another job during search process. At the same time, the literature shows that since 2005, the increase in the number of medical students enrolled has been much lower than the increase in the number of university enrollees. And, compared with senior doctors over the age of 45 , young doctors aged 26 to 35 are more likely to leave public hospitals. Public hospitals are gradually losing fresh blood.

\section{THE ROLE OF ENTERPRISE SALARY MANAGEMENT IN THE MANAGEMENT OF PUBLIC HospitALS}

The essence of an enterprise is a production-oriented profit organization. The fundamental starting point of organizational behavior is to obtain profits, while the fundamental purpose of the existence of a public institution is public service. Enterprise management has achieved complete theoretical and practical achievements in its long history of development, and as a social organization and institution, it may dialectically learn from certain enterprise management experience in the difficult management process, and there are already pioneers. The enterprise-oriented management model is an inevitable trend of public institutions under the market economy. The particularity of the public hospital industry is incumbent on it.

First of all, the suddenness and severity of the hospital's work determines that it must maintain an efficient operation, and employees must maintain good enthusiasm in their work. Some common problems of employees in public institutions, such as laziness and ease, are absolutely not allowed in hospitals. As an important means of employee motivation, business model of compensation incentives is undoubtedly more suitable.

Secondly, public hospitals, as half-government-funded institutions, have to consider benefits, management, and personnel incentives in order to survive and develop. As an important financial indicator of an organization, payroll expenses need to be inspired by business management and develop a set of scientifically appropriate models.

Third, as a senior intellectual, medical staff in public hospitals often have higher-level needs, such as self-fulfillment needs. An enterprise-based compensation mechanism can motivate the employees' self-motivation, make them feel more satisfied in their work, and ultimately improve organizational effectiveness.

\section{WAYS TO IMPROVE THE COMPENSATION MANAGEMENT MECHANISM IN PUBLIC HOSPITALS}

\section{A. Appropriately Increase The Proportion Of Doctor's Salary}

As a technology and labor-intensive industry, hospital expenses should take a considerable proportion of personnel costs. Compared with the proportion of remuneration of about $60 \%$ of public hospitals in developed countries, the cost of medical personnel in public hospitals in developed cities in China accounts for only $23 \%$ to $28 \%$ of the total expenditure, which is far lower than the procurement costs for medicines and medical equipment. From the hospital level, under the condition that the national uniform salary level salary is fixed, it is necessary to increase post salary and performance salary by appropriately increasing the proportion of personnel costs, so as to provide doctors in the hospital with the level of local development and labor value, and promote work motivation.

\section{B. Establish A Salary System Based On Job And Performance}

First, establish a post-based compensation system to address the internal inequities that exist in the old system. Post evaluation of various types of clinicians to determine their basic pay scales. Secondly, conduct a wide range of salary surveys, focus on understanding the salary levels of large and medium-sized public hospitals in the surrounding areas, and actively pay attention to the private hospitals' remuneration. Third, we must pay attention to the set-up plan for performance-based wages and fundamentally change the distribution standards and distribution basis for performancebased wages. The formulation of performance appraisal standards requires multiple perspectives, extensive coverage, and deep investigations to dynamically consider multiple dimensions in terms of quantity, safety, difficulty, economy, effectiveness, innovation, and satisfaction. In addition, according to the current irrational salary structure of public hospitals and the insufficient attention to non-economic compensation, hospitals should adjust the salary structure, change the situation that non-economic rewards engulfed by bonuses, and eliminate the diminishing marginal utility of economic performance compensation, so as to motivate employees better.

\section{Explore A Reasonable And Effective Performance Evaluation System And Try To Move Closer To The Salary System.}

The performance-based salary allocation method, which is linked to the hospital's economic income and the patient's spending in the personal name, is obviously not the most suitable method for the characteristics of the industry. Medical services have multiple dimensions such as quantity, safety, suitability, economy, effectiveness, and satisfaction. Different dimensions sometimes conflict with each other. Therefore, the use of accurately quantified indicators for performance evaluation of doctors' work results will become a problem.

The salary system created by the Mayo Clinic in the early part of the last century is still relevant today. The above discussion has illustrated the drawbacks of the performancebased wage model linked to the hospital's economic income and individual performance. Correspondingly, the superiority 
of the salary system can be highlighted. From the hospital's point of view, a high level of salary system can show at least the following advantages:

(1) Fixed pay incentives allow doctors to work more intensively for the patient's consideration and not be disturbed by the pay factors, making it easier to make a doctor's advice in favor of the patient, which in turn helps establish a good image of the hospital and relieves the strained relationship between doctors and patients.

(2) Eliminating quarterly performance-based compensation calculations and saving management costs.

(3) The income of doctors tends to be stable. Combining with the above proposal to increase the proportion of payroll expenses, doctors in this hospital, especially young doctors, will get a higher sense of achievement and higher job satisfaction.

(4) A person is not a complete economic person, but also a social person. Professionalism, professional ethics, and achievement goals also affect the organizational behavior of employees. According to Maslow's hierarchy of needs, doctors as a group whose overall quality is statistically superior to the overall quality of society are more likely to choose the latter in the face of material and self-fulfilling needs, and to obtain high level sense of satisfaction from it.

The salary system mentioned above is only an advanced direction of reform within the controllable scope of the hospital and should be exercised with caution. First of all, the overall salary of the doctor group must reach a relatively high level, supplemented by strict industry access mechanisms and fierce job competition, in order to eliminate the problem of lack of motivation and eating big pots of rice. By meeting the physiological needs and security needs of doctors through institutional arrangements, the level of doctors' needs is raised to the level of self-realization. This is the psychological basis of medical ethics. Therefore, high salaries and job security are the social basis for doctors' high professional ethics. The exchange of doctoral ethical standards with high salaries is recognized as a social contract, which is a reasonable system choice for patients, doctors, hospitals and even the entire society. Concrete implementation must be gradual and gradual, and in accordance with the economic development and the quality of citizens, start with performance-based pay, and then gradually advance to post salary, and ultimately achieve full salary requires national policy support.

\section{Pay Attention To Non-Economic Compensation And Improve Job Satisfaction}

Appropriately increase the proportion of non-economic compensation in the total salary, and take measures to improve the doctor's working environment and work experience. Buffetstyle benefits can be applied to give doctors personalized choices to maximize employee satisfaction under a fixed benefit budget. Appropriate set personal and group honors selection activities. Support more study and exchange opportunities and entertainment activities, etc. In addition, we must make reasonable arrangements for on-duty and try to ensure that every doctor can get enough rest time. It is also possible to make improvements in the working environment of working doctors, such as provide more comfortable tables and chairs and improve duty room conditions.

\section{E. Strengthen Exchanges Between All Aspects Of Hospitals And Stimulate Market Vitality}

Within the scope allowed by the institution framework, develop competition and cooperation with public and private hospitals in neighboring regions or even in other places, frequently carry out multi-hospital consultations, personnel exchanges, academic forums, etc. to increase understanding of competitors and give jobs fresh sense, improving doctors' overall professionalism.

\section{CONCLUSION}

The establishment of the remuneration system must be adapted to the characteristics of the industry and the organizational goals. It is necessary to thoroughly study the similarities and differences between the public hospital remuneration management and the enterprise remuneration management. Hospitals are different from productive industries in that performance cannot simply be measured by production volume or turnover. First of all, as a labor and technologyintensive industry, high-quality human resources of doctors can be said to be the most important factor in hospitals. Therefore, hospitals should pay sufficient attention to the doctor's salary status, establish a sufficient amount of budget, and change the traditional one-dimensional performance assessment program. Secondly, as a broad-based nonprofit business unit, the strategic objectives of public hospitals should not be solely the development and benefits of the hospital itself. Hospitals should carry out their work with the belief of serving patients, and pay more attention to organizational image. In the reform, they should also consider the social significance of the program. Finally, as a health institution that has been intervened by the government, although it has embarked on the path of enterprise management, due to various policy restrictions, it is not possible to let go of it. This requires hospital management to have a forward-thinking vision and extraordinary courage to create a "business-oriented management path for hospitals" in a creative way, which is the future of public hospital reform in China. 
In short, the improvement of the remuneration system is a systematic project and it is necessary to make overall planning. The remuneration system is an organic entirety composed of salary rank, position salary, performance salary, and welfare, etc., and it affects the entire body, the effect of special reform will not be ideal. Therefore, in the reform, it is necessary to plan in an integrated manner so that each component can achieve the optimal combination and be compatible with each other, so that a set of system and complete compensation system can be worked out.

\section{REFERENCES}

[1] Liu Xin. Compensation Management [M]. Beijing: China Renmin University Press, 2014, 25-26

[2] Shi Xiaolei. Research on incentives in salary management of public hospitals in Qingdao [D]. Shandong: China Ocean University, 2014.

[3] Yan Xiaoling et al. Reform of doctor's salary system in public hospitals in China [J]. Chinese Journal of Hospital Administration, 2015, 31(3): 173-175.

[4] Zhang Hua et al. Discussion on the deficiencies and reform of salary management in public hospitals in China [J]. Chinese Hospital, 2015, 19(10):54-55

[5] Wang Yanzhong. Existing problems and reform proposals of public hospital pay system in China [J]. Chinese Health Economics, 2015 , 34(1): 5-8.

[6] Zhou Zhixin. Theoretical and empirical research on relationship between salary satisfaction and physician professionalism [D], Shandong: Shandong University, 2014. 